\title{
Lectin-based analysis of fucosylated glycoproteins of human skim milk during 47 days of lactation
}

\author{
Jolanta Lis-Kuberka ${ }^{1}$ - Iwona Kątnik-Prastowska ${ }^{1}$ • Marta Berghausen-Mazur ${ }^{2}$ • \\ Magdalena Orczyk-Pawilowicz ${ }^{1}$
}

Received: 9 June 2015 /Revised: 6 August 2015 / Accepted: 10 August 2015 / Published online: 30 August 2015

(C) The Author(s) 2015. This article is published with open access at Springerlink.com

\begin{abstract}
Glycoproteins of human milk are multifunctional molecules, and their fucosylated variants are potentially active molecules in immunological events ensuring breastfed infants optimal development and protection against infection diseases. The expression of fucosylated glycotopes may correspond to milk maturation stages. The relative amounts of fucosylated glycotopes of human skim milk glycoproteins over the course of lactation from the $2^{\text {nd }}$ day to the $47^{\text {th }}$ day were analyzed in colostrums, transitional and mature milk samples of 43 healthy mothers by lectin-blotting using $\alpha 1-2-, \alpha 1-6-$, and $\alpha 1-3-$ fucose specific biotinylated Ulex europaeus (UEA), Lens culinaris (LCA), and Lotus tetragonolobus (LTA) lectins, respectively. The reactivities of UEA and LCA with the milk glycoproteins showed the highest expression of $\alpha 1-2$ - and $\alpha 1-6$-fucosylated glycotopes on colostrum glycoproteins. The level of UEAreactive glycoproteins from the beginning of lactation to the $14^{\text {th }}$ day was high and relatively stable in contrast to LCAreactive glycoproteins, the level of which significantly decreased from 2-3 to 7-8 days then remained almost unchanged until the $12^{\text {th }}-14^{\text {th }}$ days. Next, during the progression of lactation the reactivities with both lectins declined significantly. Eighty percent of $\alpha 1-2$ - and/or $\alpha 1$-6-fucosylated glycoproteins showed a high negative correlation with milk maturation. In contrast, most of the analyzed milk glycoproteins were not recognized or weakly recognized by LTA and remained at a low unchanged level over lactation. Only a $30-k D a$ milk
\end{abstract}

Magdalena Orczyk-Pawiłowicz

magdalena.orczyk-pawilowicz@umed.wroc.pl

1 Department of Chemistry and Immunochemistry, Wrocław Medical University, Bujwida 44a, 50-345 Wrocław, Poland

2 1st Department and Clinic of Gynaecology and Obstetrics, Wrocław Medical University, T. Chałubińskiego 3, 50-368 Wrocław, Poland glycoprotein was evidently LTA-reactive, showing a negative correlation with milk maturation. The gradual decline of high expression of $\alpha 1-2$ - and $\alpha 1-6-$, but not $\alpha 1-3-$, fucoses on human milk glycoproteins of healthy mothers over lactation was associated with milk maturation.

Keywords Human milk glycoproteins · Fucosylated glycotopes $\cdot$ Lactation $\cdot$ Lectins $\cdot$ Fucose

$\begin{array}{ll}\text { Abbreviations } \\ \text { HMOs } & \text { Human Milk Oligosaccharides } \\ \text { LCA } & \text { Lectin from Lens culinaris } \\ \text { LTA } & \text { Lectin from Lotus tetragonolobus } \\ \text { UEA } & \text { Lectin from Ulex europaeus } \\ \text { Fuc } & \text { fucose }\end{array}$

\section{Introduction}

Human milk of a healthy mother supports adequate growth and development of infants, covering nutrient requirements during the first 6 months of life [1-3]. Breast-feeding is connected with neurodevelopmental advantages $[1,2]$ and reduces the risk of acute and chronic diseases in the developing infant [4-7]. These properties are dependent on bioactive compounds, including fucosylated and sialylated glycoconjugates, which constitute a large part of the human milk and include free oligosaccharides (HMOs), glycoproteins, glycolipids and glycosaminoglycans [8-11]. Among milk glycoconjugates, the highly fucosylated and sialylated glycans take part in the protection of the newborn and infant from bacterial and viral infections $[4,10,12,13]$, and according to Royle et al. [14] they are among the components of the innate immune system. 
The fucose on $\mathrm{N}$ - and O-glycans of glycoproteins occurs as a terminal monosaccharide and can be linked by $\alpha 1-3 / \alpha 1-4-$ glycosidic bonds to the subterminal GlcNAc or by an $\alpha 1-2$ bond to Gal of antennae [11, 15-17]. Fucose can also be attached by $\alpha 1-6-$ linkage to GlcNAc of the core structure of $\mathrm{N}$-glycans and is referred to as the core fucose or innermost fucose [11, 15-17]. The fucosylated human milk glycoproteins, similar to fucosylated plasma glycoproteins, can take part in biological recognition reactions, and their expression is reported to be bound with pathophysiological status. $\alpha 1-6-$ linked fucose controls many biological reactions such as cellcell signaling and adhesion, stimulates cell growth and differentiation and modulates IgG1-type antibody-dependent cellular cytotoxicity $[15,18]$. Outer arm $\alpha 1-2-$ and $\alpha 1-3$-linked fucoses are a part of the Lewis family glycotopes expressed on N- and O-glycans of glycoproteins [15-17] and can be recognized and bound by the lectin- receptors of bacteria and/or viruses, and in that way by blocking of lectin- receptors of pathogens prevent their adhesion to the host epithelial cells and prevent colonization and invasion of mucosa $[5,7,11$, 19-21]. On the other hand, $\alpha 1-3$-linked fucose is a part of the Lewis ${ }^{\mathrm{x}}$ and sialo-Lewis ${ }^{\mathrm{x}}$ antigens, which are ligands for L-, E-, and P-selectins [15, 22]. According to Bernardi et al. [21], the multivalent presentation of mostly larger and branched glycoprotein glycans could provide a better mechanism of pathogen capture than the simple and relatively small structures of HMOs. The presence or absence of $\alpha 1-2-$ fucosylated glycotopes on cellular and soluble glycoconjugates of secretions (saliva, milk, semen) is genetically determined as secretor status. The milk of women who are secretors contains a higher amount of fucosylated glycoconjugates, which are closely connected with antimicrobial properties of human milk [reviewed in [7, 11, 20, 23]]. It has been shown that fucosylated glycoproteins of human milk inhibit binding of Campylobacter jejuni [24], enteropathogenic Escherichia coli (EPEC) [25], Helicobacter pylori [26], Salmonella enterica serovar Typhimurium and Heidelberg [6, 27], Noroviruses [28] and human immunodeficiency virus (HIV) to the host cells $[29,30]$. It was also reported that $\alpha 1$-2-linked fucose has a potential to modulate growth, communication, and regeneration of neurons and can take part in forming long-term memory [31, 32]. Moreover, fucosylated glycans of milk glycoconjugates can be degraded by bacterial fucosidases produced in particular by Bifidobacterium species, which in this way can gain access to the energetic content of milk and predominance in the intestinal microbiota in the first year of infant life $[11,33]$.

The analysis of glycoprotein pattern in a human milk sample is complex, mainly because of different amounts of individual glycoproteins in the total pool and alterations in their concentration over lactation. Methods such as high performance liquid chromatography (HPLC) and mass spectrometry (MS) have been used for such determinations, but they are limited to selected stages of lactation as well as to a low number of samples analyzed [34]. Nwosu and coworkers [34] reported high fucosylation $(75 \%)$ and lower sialylation (57\%) of human milk N-glycans, but the analysis was limited to mature milk only. On the other hand, the detailed analysis of human milk oligosaccharides reported by De Leoz et al. [23] revealed that $63.5 \%$ of them are fucosylated. To date, the knowledge concerning lactation-stage related glycovariants in human milk glycoproteome is limited to the major glycoproteins (S-IgA [14, 35], lactoferrin [6, 36], mucins [37]) and is mainly restricted to the selected weeks of lactation. A semiquantitative overview of glycoprotein expression and changes in glycosylation profile of selected human milk glycoproteins during lactation was published by Froehlich [36]. Moreover, the sialylation and fucosylation of $\alpha-1$-acid glycoprotein [38], fibronectin [39] and bile-salt-stimulated lipase (BSSL) [40] are lactation-stage related. Additionally, Gustafsson and coworkers [41] have shown that expression of fucosylated and sialylated glycotopes on human milk glycoproteins is the most complex one, and similar expression to that was observed for pig and horse but not for bovine milk proteins.

The aim of this study was to investigate the expression of $\alpha 1-2-, \alpha 1-3-$ and $\alpha 1-6$ - fucosylated glycotopes on human milk glycoproteins during the progression of milk maturation over 2-47 days of a healthy mother's lactation. The fucosylated glycotopes on human milk glycoproteins were analyzed semi-quantitatively by lectin-blotting using lectins able to recognize and differentiate the type of glycosidic linkage to the oligosaccharide backbone and specific to $\alpha 1$-2-linked (UEA: Ulex europaeus lectin), $\alpha 1-6$-linked (LCA: Lens culinaris lectin), and $\alpha 1-3$-linked (LTA: Lotus tetragonolobus lectin) fucoses. The application of lectins has been especially helpful in obtaining information about the expression of biologically active glycotopes in their conformational native form, exposed and ready to react with natural receptors, such as endogenous selectins and bacterial lectins. Moreover, a lectin-based test allowed for simultaneous analysis of many milk glycoproteins and avoided a labor- and cost intensive procedure of isolation of individual glycoproteins. The analyses of milk samples obtained from healthy mothers were performed in the groups of colostrum of days 2,3 , and 4-5, transitional milk days $7-8,10$, and $12-14$, and mature milk days $15-17,30-35$, and $39-47$. The analysis of obtained data allowed us to observe the types of fucosylation changes associated with the milk maturation process.

\section{Materials and methods}

\section{Participants}

Samples of milk ( $n=43)$ were obtained from healthy lactating women (from 21 to 35 years old) receiving regular perinatal 
care at the $1^{\text {st }}$ Department of Gynecology and Obstetrics at Wroclaw Medical University, Wroclaw, Poland. For inclusion in the study, participants had to have a good state of health and normal uncomplicated pregnancy. Women who used tobacco products, illicit drugs, or alcohol or with abnormal lactation (e.g., mastitis) or were pregnant with multiple fetuses were excluded. All mothers who agreed to give their milk for the biochemical research were acquainted with the protocol approved by the Ethics Committee at Wroclaw Medical University (number KB-30/2013). Informed consent was obtained from all participants.

\section{Sample collection and preparation}

Samples of human milk from 2 to 47 days of lactation were collected by a trained nurse from the breast by manual expression at the end of nursing (hindmilk) by complete breast emptying, once per day, at the same time (8:00-10:00 a.m.). All milk samples were frozen in plastic containers and stored immediately at $-20{ }^{\circ} \mathrm{C}$ until analysis. Skim milk (aqueous phase) was prepared by centrifugation at $3,500 \mathrm{~g}$ at $4{ }^{\circ} \mathrm{C}$ for $35 \mathrm{~min}$, after which the fat layer and cells were removed. The samples of skim human milk were stored at $-20{ }^{\circ} \mathrm{C}$, and before the analysis, the aliquots of the human skim milk samples were kept for $1 \mathrm{~h}$ at room temperature.

For analysis of fucosylation of milk glycoproteins, the samples were collected only from mothers who have secretor status with $\mathrm{Se}+\mathrm{Le}+$ fenotype (information obtained from previous studies [38, 39]). To minimize the impact of individual differences among the mothers, the selected milk samples from the same period of the successive stages of lactation were pooled before analysis by mixing an equal volume of $200 \mu \mathrm{L}$ of an individual skim milk sample. The following groups were formed:

(1) colostrum (Day 2 of lactation; $n=2$ ),

(2) colostrum (Day 3 of lactation; $n=5$ ),

(3) colostrum (Day 4-5 of lactation; $n=7$ ),

(4) transitional milk (Day 7-8 of lactation; $n=5$ ),

(5) transitional milk (Day 10 of lactation; $n=4$ ),

(6) transitional milk (Day 12-14 of lactation; $n=5$ ),

(7) mature milk (Day 15-17 of lactation; $n=5$ ),

(8) mature milk (Day 30-35 of lactation; $n=5$ ),

(9) mature milk (Day 39-47 of lactation; $n=5$ ).

\section{Methods}

\section{Determination of protein concentration}

The total protein concentration in human skim milk pooled samples was determined by bicinchoninic methods with the
Bicinchoninic Acid Protein Assay Kit (Sigma, St. Louis, MO, USA) and bovine albumin as a standard.

For the analysis, $0.5 \mu \mathrm{l}$ of human pooled skim milk, $24.5 \mu \mathrm{l}$ of $0.9 \% \mathrm{NaCl}$ and $200 \mu \mathrm{l}$ of freshly prepared bicinchoninic acid working reagent (solution of bicinchoninic acid and copper (II) sulfate in the ratio 1:50, respectively) were added to the same well of microtiter plates, and were incubated at $37.5^{\circ} \mathrm{C}$ for $30 \mathrm{~min}$. The absorbance was measured in a Stat Fax 2100 Microplate Reader (Awareness Technology Inc., Palm City, Florida, USA) at $560 \mathrm{~nm}$. All samples were analyzed in duplicate.

\section{SDS- electrophoresis}

The skim milk pooled sample containing $30 \mu \mathrm{g}$ of protein was denatured at $100{ }^{\circ} \mathrm{C}$ for $5 \mathrm{~min}$ in the presence of $5 \% \beta$ mercaptoethanol, $10 \%$ glycerol, $2 \%$ SDS, $1 \mathrm{M}$ Tris- $\mathrm{HCl}$ $\mathrm{pH} 6.8$, and loaded to SDS-PAGE in a $7.5 \%$ gel, according to Laemmli [42]. The electrophoresis was carried out in $0.1 \%$ SDS buffer (25 mM Tris, $0.192 \mathrm{M}$ glycine, $0.1 \%$ SDS, $\mathrm{pH} 8.3$ ) at $200 \mathrm{~V}$ for $50 \mathrm{~min}$ in the electrophoresis apparatus (Bio- Rad Laboratories) until bromophenol reached the point of $0.5 \mathrm{~cm}$ to the end of the agarose gel. After electrophoresis, the separated skim milk proteins were transferred onto nitrocellulose membrane (Serva Electrophoresis GmbH, Heidelberg, Germany) according to the Towbin method [43] for $1.5 \mathrm{~h}(250 \mathrm{~mA})$.

\section{Colloidal silver staining}

After transfer of separated glycoproteins onto nitrocellulose, the membrane was washed in deionized water and stained with a colloidal silver staining solution [44], prepared by mixing of $2.5 \mathrm{ml}$ of $40 \%$ sodium citrate dihydrate, $2 \mathrm{ml}$ of $20 \%$ ferrous sulfate heptahydrate (freshly prepared), $0.5 \mathrm{ml}$ of $20 \%$ silver nitrate and $45 \mathrm{ml}$ of deionized water. The colloidal silver staining lasted $10 \mathrm{~min}$ and was stopped by adding deionized water. The membrane was dried, scanned, and analyzed. The colloidal silver staining was carried out twice, and the results are presented as the mean value obtained from two experiments.

\section{Lectin- blotting}

The reactivities of fucose-specific lectins with human skim milk glycoprotein bands were analyzed by lectin- blotting using UEA, LCA and LTA biotin-labeled lectins (Vector Laboratories Inc., Burlingame, USA) with well-known specificity (Table 1). The lectin- blotting details are as follows: after the SDS-PAGE, the separated milk proteins as well as positive (human haptoglobin and an asialo-haptoglobin preparation derived from ovarian cancer fluid) [45] and negative (human albumin) controls were transferred onto nitrocellulose 
Table 1 Major binding characteristics of some fucose-specific lectins

Origin and used abbreviation of lectin Binding preferences

Ulex europaeus agglutinin (UEA)

Fucose linked $\alpha 1-2$ to $\mathrm{Gal}$ of $\mathrm{N}$ - and $\mathrm{O}$-glycans $[54,55]$

Lens culinaris agglutinin (LCA)

Fucose linked $\alpha 1-6$ to proximal GlcNAc of the trimannosyl core of biantennary $\mathrm{N}$-glycans [56]

Lotus tetragonolobus agglutinin (LTA)

Fucose linked $\alpha 1-3$ to subterminal GlcNAc of $\mathrm{N}$ - and O-glycans $[55,57]$

membrane, and then the membrane was blocked with $2 \%$ Tween-20 in TBS, pH 7.5 at $32{ }^{\circ} \mathrm{C}$ for $1 \mathrm{~h}$. After washing with $0.1 \%$ Tween-20 in TBS (TBS-T) (at $32{ }^{\circ} \mathrm{C}$ for $1 \times 15$ and $2 \times 5 \mathrm{~min}$ ), the membranes were incubated with biotinlabeled lectins: UEA $(2 \mu \mathrm{g} / \mathrm{ml})$, LCA $(0.4 \mu \mathrm{g} / \mathrm{ml})$, and LTA $\left(4 \mu \mathrm{g} / \mathrm{ml}\right.$ ) for $1 \mathrm{~h}$ at $32{ }^{\circ} \mathrm{C}$ in TBS containing $0.1 \%$ Tween 20 , $1 \mathrm{mM} \mathrm{MgCl}_{2}, 1 \mathrm{mM} \mathrm{CaCl}_{2}, 1 \mathrm{mM} \mathrm{MnCl} 2, \mathrm{pH}$ 7.5. The formed lectin-glycoprotein complex was detected by the reaction with ExtrAvidin phosphatase-labeled (Sigma, St. Louis, MO, USA) diluted 1:20 000 in TBS containing 0.1\% Tween 20, pH 7.5 (blots were incubated at $32{ }^{\circ} \mathrm{C}$ for $1 \mathrm{~h}$ ). After washing with TBS-T, the colored reaction was developed by incubating the nitrocellulose in a freshly prepared solution: $80 \mu \mathrm{l}$ of BCIP-phosphate (5-bromo-4-chloro-3indolylphosphate, Sigma, St. Louis, MD, USA) and $80 \mu \mathrm{l}$ of NBT-chloride (nitroblue tetrazolium chloride, Sigma, St. Louis, MD, USA) in $8 \mathrm{ml}$ of $0.1 \mathrm{M}$ Tris/ $\mathrm{HCl}, \mathrm{pH} 9.5$, containing $0.05 \mathrm{M} \mathrm{MgCl}_{2}, 0.1 \mathrm{M} \mathrm{NaCl}$ at room temperature for $50 \mathrm{~s}$. The blots with all lectins were carried out twice, and the results are presented as the mean value obtained from two experiments.

\section{Densitometric analysis}

The intensity of bands obtained after silver staining and lectinblotting corresponded to the amount of proteins per band and lectin reactivity with the particular fucosylated glycoproteins of skim milk, respectively. The intensity of each line from blots was quantified by densitometric analysis with the myImageAnalysis software (Thermo Scientific, New Hampshire). The relative amount of protein bands and the fucosylated glycotopes on each glycoprotein band was expressed as a mean of pixels $\times 10^{6}$ for the individual band obtained from two blots.

\section{Glycoprotein molecular mass determination}

To determine the molecular mass of separated human skim milk glycoproteins, the Precision Plus Protein standards for SDS-PAGE (Bio-Rad) containing 10 protein standards with

molecular mass ranging from 250 to $10 \mathrm{kDa}$ were used. Based on molecular mass of standards, a calibration curve of the log of molecular mass $(\mathrm{Mm})$ versus $\mathrm{R}_{\mathrm{f}}$ was generated.

\section{Statistical analysis}

The statistical analysis was performed with the STATISTICA 10.0 software package (StatSoft, Inc., Tulsa, OK, USA). The correlations were estimated according to Spearman. A $p$-value lower than 0.05 was regarded as significant.

\section{Results}

\section{SDS-PAGE pattern of human skim milk proteins}

Among ten milk protein bands revealed by SDS-PAGE and showing molecular masses ranging from 30 to $310 \mathrm{kDa}$, the most abundant were three: $260-310 \mathrm{kDa}(17.7 \%), 78-86 \mathrm{kDa}$ $(26.1 \%)$ and $35-50 \mathrm{kDa}(25.1 \%)$ on the first 3 days of lactation (Fig. 1, Table 2).

Over milk maturation the relative amounts of the 260-310 and $35-50 \mathrm{kDa}$ bands showed a high negative correlation with the day of lactation ( $r=-0.87$ and -0.92 , respectively). In contrast, the relative amounts of the 220-225,160-175, 155, 133, 78-86, 70-75, 63-67 and $30 \mathrm{kDa}$ protein bands did not significantly change during the course of lactation (Fig. 1, Table 2).

\section{Fucose-specific lectin- reactivity with human milk} glycoproteins

The lectin- blotting pattern of human skim milk glycoproteins over the course of lactation showed strong reactivities with

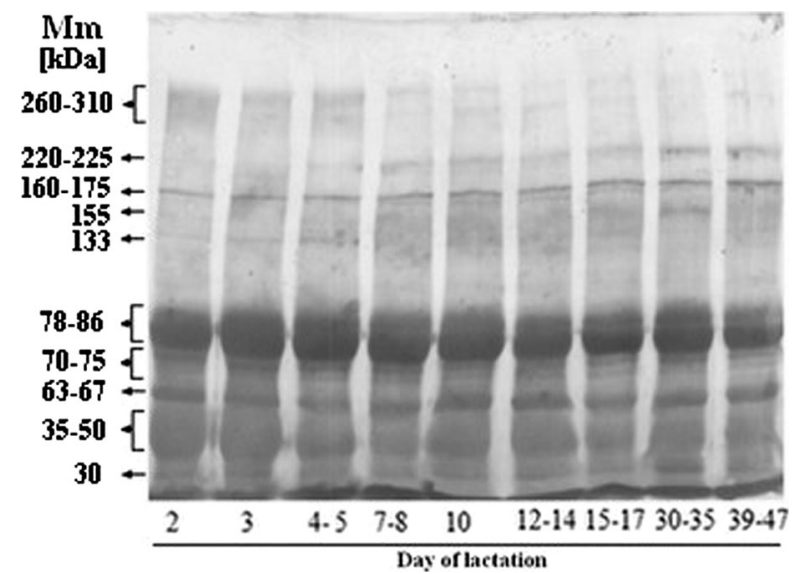

Fig. 1 Representative patterns of human skim milk proteins over lactation. A human skim milk sample containing $30 \mu \mathrm{g}$ of proteins was loaded per lane of SDS-PAGE. After separation the proteins were transferred onto nitrocellulose, and the membrane was stained with a colloidal silver [44]. For experimental details see Material and methods 
Table 2 Relative amounts of human skim milk proteins over lactation

\begin{tabular}{|c|c|c|c|c|c|c|c|c|c|c|}
\hline \multirow[t]{2}{*}{ Mm of protein band $[\mathrm{kDa}]$} & \multicolumn{9}{|c|}{$\begin{array}{l}\left.\text { Relative amounts of the protein bands [pixels } \times 10^{6}\right] \text { shown in Fig. } 1 \\
\text { Day of lactation }\end{array}$} & \multirow[t]{2}{*}{$\mathrm{r}$} \\
\hline & $2^{\text {nd }}$ & $3^{\text {rd }}$ & $4^{\text {th }}-5^{\text {th }}$ & $7^{\text {th }}-8^{\text {th }}$ & $10^{\text {th }}$ & $12^{\text {th }}-14^{\text {th }}$ & $15^{\text {th }}-17^{\text {th }}$ & $30^{\text {th }}-35^{\text {th }}$ & $39^{\text {th }}-47^{\text {th }}$ & \\
\hline $260-310$ & 41.0 & 32.0 & 30.0 & 18.0 & 18.0 & 18.0 & 15.0 & 8.2 & 18.0 & -0.87 \\
\hline $220-225$ & 8.3 & 10.0 & 6.7 & 8.7 & 10.0 & 8.1 & 9.6 & 13.0 & 11.0 & NS \\
\hline $160-175$ & 9.2 & 6.8 & 11.0 & 9.2 & 7.6 & 7.9 & 9.9 & 9.0 & 10.0 & NS \\
\hline 155 & 9.7 & 11.0 & 9.6 & 11.0 & 13.0 & 12.0 & 13.0 & 8.2 & 12.0 & NS \\
\hline 133 & 8.4 & 6.6 & 8.0 & 4.8 & 8.0 & 6.9 & 8.6 & 8.5 & 7.7 & NS \\
\hline $78-86$ & 53.0 & 59.0 & 63.0 & 58.0 & 57.0 & 52.0 & 53.0 & 58.0 & 49.0 & NS \\
\hline $70-75$ & 18.0 & 19.0 & 16.0 & 17.0 & 20.0 & 15.0 & 16.0 & 17.0 & 18.0 & NS \\
\hline $63-67$ & 18.0 & 17.0 & 14.0 & 17.0 & 18.0 & 18.0 & 17.0 & 20.0 & 16.0 & NS \\
\hline $35-50$ & 58.0 & 57.0 & 49.0 & 44.0 & 45.0 & 46.0 & 41.0 & 43.0 & 40.0 & -0.92 \\
\hline 30 & 8.8 & 9.4 & 8.9 & 11.0 & 8.7 & 10.0 & 8.2 & 10.0 & 8.1 & NS \\
\hline
\end{tabular}

The pattern of bands shown in Fig. 1 was analyzed using myImageAnalysis software (Thermo Scientific, New Hampshire)

The relative amount of protein bands was expressed as the mean number of pixels $\times 10^{6}$ obtained from two blots

$\mathrm{r}$ - correlation coefficient with lactation days

$N S$ not significant with a $p$-value equal to or higher than 0.05

UEA and LCA, but with LTA remained (if at all) at a low level (Fig. 2). The semi-quantitative differences between the particular milk glycoprotein-lectin reactivities over the course of lactation are given in Table 3.

\section{Expression of UEA-reactive bands}

The UEA- reactivity (Fig. 2a, Table 3 ) of the 220-225, 160175 , and $35-50 \mathrm{kDa}$ glycoproteins showed a strong negative correlation over the progression of lactation $(\mathrm{r}=-0.77,-0.72$ and -0.77 , respectively) (Table 3 ), whereas the reactivity of the $133 \mathrm{kDa}, 78-86,70-75,63-67$, and $30 \mathrm{kDa}$ glycoproteins did not (Table 3). Moreover, the 260-310 and $155 \mathrm{kDa}$ glycoproteins lacked the UEA-reactive glycotopes during the course of lactation, but with time-dependent exceptions, i.e., low UEAreactivity observed for the colostrum sample from the $2^{\text {nd }}$ day and the mature milk samples from the $15^{\text {th }}-47^{\text {th }}$ days, respectively.

\section{Expression of LCA-reactive bands}

The LCA- reactivity (Fig. 2b, Table 3 ) of the $260-310 \mathrm{kDa}$ $(\mathrm{r}=-0.85), 160-175 \mathrm{kDa}(-0.83), 133 \mathrm{kDa}(\mathrm{r}=-0.81), 78-$ $86 \mathrm{kDa}(-0.85), 70-75 \mathrm{kDa}(\mathrm{r}=-0.70), 35-50 \mathrm{kDa}(\mathrm{r}=-0.87)$ and $30 \mathrm{kDa}(\mathrm{r}=-0.75)$ glycoprotein bands showed a strong negative correlation over the progression of lactation. In contrast, the relative reactivities of LCA-reactive glycotopes of 220-225 and 63-67 kDa glycoproteins did not significantly change over the progression of lactation. The $155 \mathrm{kDa}$ band was not recognized by LCA over lactation with the exception of low reactivity ( $1.9 \%$ ) observed on the $2^{\text {nd }}$ day of lactation (Table 3).

\section{Expression of LTA-reactive bands}

LTA reacted with $30,35-50,63-67,70-75,78-86$ and 160 $175 \mathrm{kDa}$ glycoproteins of human milk (Fig. 2c, Table 3), but only the $30 \mathrm{kDa}$ band showed a negative correlation $(\mathrm{r}=-0.78)$ with progression of lactation. In contrast, the 260-310, 220 225,155 and $133 \mathrm{kDa}$ bands were not recognized by LTA at all (Table 3).

\section{Pattern of fucose-specific lectin- reactivity with human milk glycoproteins}

Based on the analyses of the fucosyl-lectin reactivities of milk glycoproteins over the progression of lactation, two general types of changes were selected (Fig. 3). The first one (Fig. 3a) was associated with a significant decline of reactivities of milk UEA-reactive- (220-225 kDa, $160-175 \mathrm{kDa}, 35-50 \mathrm{kDa})$, LCA-reactive- glycoproteins $(260-310 \mathrm{kDa}, 160-175 \mathrm{kDa}$, $133 \mathrm{kDa}, 133 \mathrm{kDa}, 78-86 \mathrm{kDa}, 70-75 \mathrm{kDa}, 35-50 \mathrm{kDa}$, $30 \mathrm{kDa}$ ), and only one, the LTA-weakly reactive $30 \mathrm{kDa}$ glycoprotein (Fig. 3a). The UEA- and LCA-reactive glycoproteins, but not LTA-reactive 30-kDa glycoprotein, showed the characteristic decline patterns. However, the level of UEAreactive glycoproteins from the beginning of lactation $\left(2^{\text {nd }}-\right.$ $3^{\text {rd }}$ day) to the $12^{\text {th }}-14^{\text {th }}$ day of lactation was relatively stable, in contrast to LCA-reactive glycoproteins, whose level significantly decreased from 2-3 to 7-8 days and remained almost unchanged until the $12^{\text {th }}-14^{\text {th }}$ day. During the 


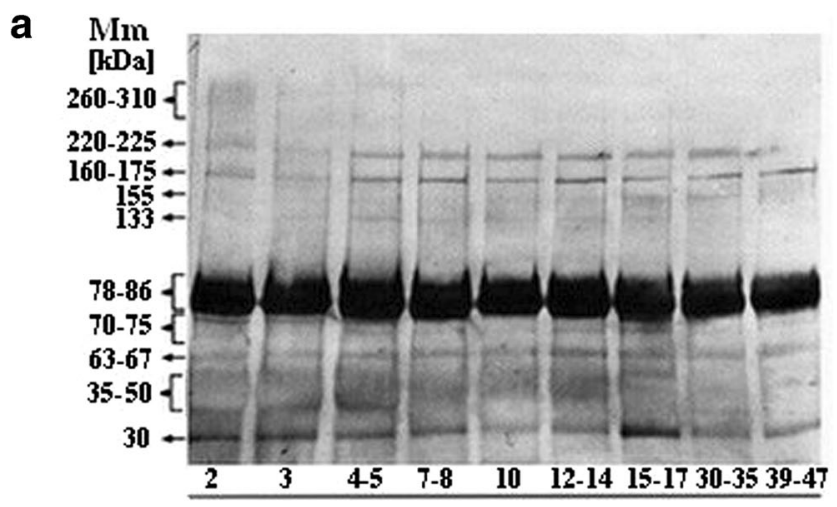

b

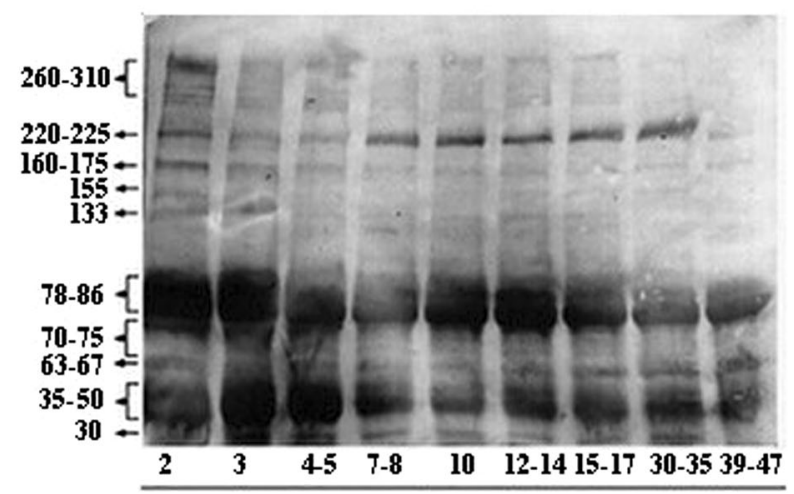

C

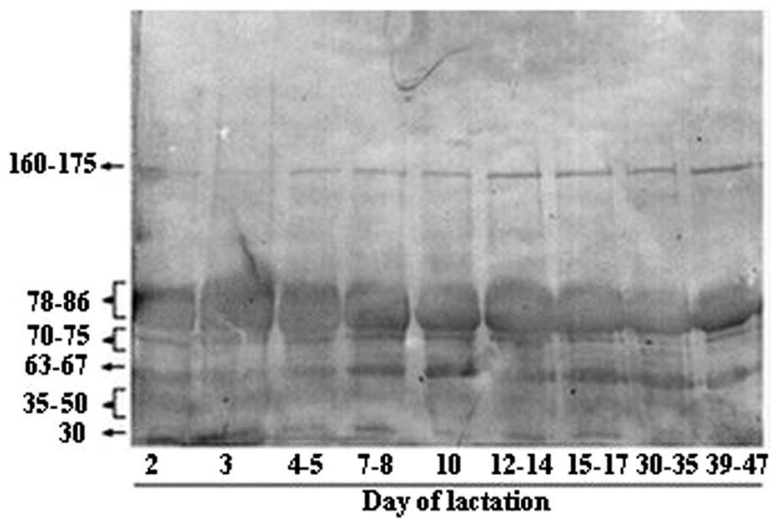

Fig. 2 Representative patterns of human milk glycoprotein reactivities with fucose-specific lectins over lactation. For analysis of fucosylation of milk glycoproteins, the samples were collected only from mothers who have secretor status. The pooled milk sample containing $30 \mu \mathrm{g}$ of proteins was loaded per lane of SDS-PAGE. After separation, the glycoproteins were transferred onto nitrocellulose, and the membrane was subjected to the reaction with (a) Ulex europaeus, (b) Lens culinaris, and (c) Lotus tetragonolobus biotinylated lectin (Vector Laboratories Inc. Burlingame. USA), respectively. The formed lectin-glycoprotein complex was detected by the reaction with phosphatase-labeled ExtrAvidin (Sigma. St. Louis. MO. USA). All blots were done in duplicate. For experimental details see Material and methods

progression of lactation from the $15^{\text {th }}-17^{\text {th }}$ days to the $39^{\text {th }}-$ $47^{\text {th }}$ days the reactivities of UEA and LTA with milk glycoproteins significantly decreased (Fig. 3a).

The second type of changes during the $2^{\text {nd }}$ and $39^{\text {th }}-47^{\text {th }}$ days of lactation was related to a gradual, but insignificant decrease of UEA- (260-310 kDa, $133 \mathrm{kDa}, 78-86 \mathrm{kDa}, 70$
$75 \mathrm{kDa}, 63-67 \mathrm{kDa}, 30 \mathrm{kDa})$, and LCA-reactive (220$225 \mathrm{kDa}, 63-67 \mathrm{kDa}$ ) milk glycoproteins (Fig. 3b), and LTA-weakly reactive at a rather stable low level (160$175 \mathrm{kDa}, 78-86 \mathrm{kDa}, 70-75 \mathrm{kDa}, 63-67 \mathrm{kDa}, 35-50 \mathrm{kDa})$ and non-LTA-reactive $(260-310 \mathrm{kDa}, 220-225 \mathrm{kDa}$, $133 \mathrm{kDa}$ ) milk glycoproteins (Fig. 3b).

\section{Discussion}

The study shows that despite the individual differences in fucosylation of particular human milk glycoproteins, the gradual decline of highly expressed $\alpha 1-2$ - and $\alpha 1-6$-fucosylated glycotopes on human milk glycoproteins over lactation was associated with milk maturation, in contrast to a relatively constant low expression or absence of $\alpha 1-3$-fucosylated glycotope.

Among ten protein bands revealed by SDS-PAGE and silver staining (Fig. 1) nine bands, excluding the $155 \mathrm{kDa}$ band, were evidently fucosylated (Fig. 2). The $155-\mathrm{kDa}$ protein is either not fucosylated or its glycotopes are hidden. The fucosylated glycoproteins were recognized by the lectin reagents in vitro (Table 2), and being exposed on milk glycoproteins are ready for specific interactions with endogenous respective lectins, in vivo. The milk glycoproteins were heavily decorated with $\alpha 1$-2-linked fucose, to a lesser degree with $\alpha 1-6$-linked fucose, and weakly, if at all, with $\alpha 1-3$-linked fucose. Based on the degree of reactivity of fucose-specific lectins with particular skim milk glycoproteins, two types of general patterns of $\alpha 1-2-, \alpha 1-6-$, and $\alpha 1-3-$ linked fucose expression over normal lactation might be distinguished (Fig. 3a and b). The first comprises the glycoproteins which showed significant decreases in the $\alpha 1-2$ - (3 glycoprotein bands), $\alpha 1$ 6- (7 glycoprotein bands), and $\alpha 1-3$-linked fucose ( 1 glycoprotein band) expression (Fig. 3a) in relation to physiological stages of milk maturation, and the second was variable but did not show a statistically significant correlation (Fig. 3b). Interestingly, a high negative correlation over the progression of milk maturation was shown by about 30,70 , and $10 \%$ of $\alpha 1$ 2-, $\alpha 1-6-$, and $\alpha 1-3$-fucosylated glycoproteins, respectively. These glycoproteins showed their highest relative reactivities with UEA, LCA, and LTA in the colostrum at the beginning of lactation (Fig. 3a). Furthermore, over the progression of lactation the profile of fucosyl-glycotope expression differed in relation to the type of glycosidic bond, which links a fucose to the oligosaccharide part of glycoprotein. The high expression of the $\alpha 1-2$-linked fucose remained at a nearly stable level from the beginning of lactation up to the $14^{\text {th }}$ day of lactation, i.e., from colostrums to the transitional milk, and further decreased intensively, reaching about a 6- times lower reactivity value in mature milk. Also, the profile of the $\alpha 1-6$-fucose expression on milk glycoproteins corresponded to milk maturation intervals (Fig. 3a), but its profile differs from that of the 
Table 3 Relative amounts of $\alpha 1-2-, \alpha 1-3-$ and $\alpha 1-6$-fucosylated glycotopes on human skim milk glycoproteins over lactation

\begin{tabular}{|c|c|c|c|c|c|c|c|c|c|c|c|}
\hline \multirow[t]{2}{*}{$\mathrm{Mm}$ of protein band $[\mathrm{kDa}]$} & \multirow[t]{2}{*}{$\begin{array}{l}\text { Lectin (glycotope } \\
\text { recognized) }\end{array}$} & \multicolumn{9}{|c|}{$\begin{array}{l}\text { Relative amounts of the glycotope [pixels } \times 10^{6} \text { ] revealed by lectin-immunoblotting } \\
\text { shown in Fig. } 2 \\
\text { Day of lactation }\end{array}$} & \multirow[t]{2}{*}{$\mathrm{r}$} \\
\hline & & $2^{\text {nd }}$ & $3^{\mathrm{rd}}$ & $4^{\text {th }}-5^{\text {th }}$ & $7^{\text {th }}-8^{\text {th }}$ & $10^{\text {th }}$ & $12^{\text {th }}-14^{\text {th }}$ & $15^{\text {th }}-17^{\text {th }}$ & $30^{\text {th }}-35^{\text {th }}$ & $39^{\text {th }}-47^{\text {th }}$ & \\
\hline \multirow[t]{3}{*}{$260-310$} & UEA ( $\alpha 1-2-F u c)$ & 9.5 & 0 & 0 & 0 & 0 & 0 & 0 & 0 & 0 & ND \\
\hline & LCA ( $\alpha 1-6-F u c)$ & 14.9 & 5.3 & 4.2 & 1.0 & 1.5 & 2.1 & 1.7 & 0 & 0 & -0.85 \\
\hline & LTA ( $\alpha 1-3-$ Fuc $)$ & 0 & 0 & 0 & 0 & 0 & 0 & 0 & 0 & 0 & ND \\
\hline \multirow[t]{3}{*}{$220-225$} & UEA ( $\alpha 1-2-$ Fuc) & 5.0 & 3.8 & 4.6 & 6.2 & 4.6 & 4.1 & 3.8 & 3.1 & 1.2 & -0.77 \\
\hline & LCA ( $\alpha 1-6-F u c)$ & 5.3 & 4.0 & 4.5 & 5.3 & 6.9 & 5.3 & 5.2 & 5.4 & 2.6 & NS \\
\hline & LTA ( $\alpha 1-3-$ Fuc $)$ & 0 & 0 & 0 & 0 & 0 & 0 & 0 & 0 & 0 & ND \\
\hline \multirow[t]{3}{*}{$160-175$} & UEA ( $\alpha 1-2-$ Fuc) & 6.6 & 5.8 & 6.9 & 6.9 & 5.1 & 6.1 & 4.4 & 3.8 & 4.5 & -0.72 \\
\hline & LCA ( $\alpha 1-6-F u c)$ & 5.3 & 3.4 & 3.5 & 2.3 & 3.8 & 2.9 & 2.1 & 2.2 & 2.0 & -0.83 \\
\hline & LTA ( $\alpha 1-3-$ Fuc) & 1.6 & 1.2 & 1.0 & 1.1 & 1.2 & 1.4 & 1.5 & 1.4 & 1.7 & NS \\
\hline \multirow[t]{3}{*}{155} & UEA ( $\alpha 1-2-F u c)$ & 0 & 0 & 0 & 0 & 0 & 0 & 3.8 & 3.4 & 2.1 & ND \\
\hline & LCA ( $\alpha 1-6-$ Fuc) & 2.4 & 0 & 0 & 0 & 0 & 0 & 0 & 0 & 0 & ND \\
\hline & LTA ( $\alpha 1-3-$ Fuc) & 0 & 0 & 0 & 0 & 0 & 0 & 0 & 0 & 0 & ND \\
\hline \multirow[t]{3}{*}{133} & UEA ( $\alpha 1-2-F u c)$ & 2.4 & 2.7 & 3.2 & 1.7 & 2.6 & 1.8 & 3.0 & 0 & 0 & NS \\
\hline & LCA ( $\alpha 1-6-F u c)$ & 2.8 & 2.8 & 1.7 & 1.5 & 1.8 & 1.9 & 0 & 0 & 0 & -0.81 \\
\hline & LTA ( $\alpha 1-3-$ Fuc) & 0 & 0 & 0 & 0 & 0 & 0 & 0 & 0 & 0 & ND \\
\hline \multirow[t]{3}{*}{$78-86$} & UEA ( $\alpha 1-2-F u c)$ & 78.7 & 82.1 & 80.9 & 82.4 & 75.0 & 83.7 & 79.8 & 69.8 & 69.1 & NS \\
\hline & LCA ( $\alpha 1-6-$ Fuc) & 48.0 & 45.8 & 37.3 & 37.1 & 41.1 & 42.1 & 30.1 & 26.5 & 26.0 & -0.85 \\
\hline & LTA $(\alpha 1-3-F u c)$ & 10.9 & 11.3 & 12.9 & 13.4 & 12.9 & 14.0 & 12.1 & 11.0 & 10.6 & NS \\
\hline \multirow[t]{3}{*}{$70-75$} & UEA ( $\alpha 1-2-F u c)$ & 15.1 & 4.3 & 3.4 & 2.5 & 5.9 & 5.7 & 6.9 & 2.7 & 1.7 & $\mathrm{NS}$ \\
\hline & LCA ( $\alpha 1-6-F u c)$ & 3.2 & 3.6 & 3.5 & 2.1 & 3.6 & 3.2 & 2.5 & 1.2 & 0 & -0.70 \\
\hline & LTA ( $\alpha 1-3-$ Fuc $)$ & 1.8 & 1.8 & 2.0 & 2.1 & 2.2 & 2.1 & 2.1 & 1.8 & 1.8 & NS \\
\hline \multirow[t]{3}{*}{$63-67$} & UEA ( $\alpha 1-2-F u c)$ & 11.2 & 6.8 & 10.6 & 9.9 & 8.6 & 11.9 & 11.4 & 8.1 & 5.1 & NS \\
\hline & LCA ( $\alpha 1-6-F u c)$ & 9.8 & 5.8 & 7.1 & 9.2 & 6.6 & 6.7 & 5.6 & 4.9 & 6.4 & NS \\
\hline & LTA $(\alpha 1-3-$ Fuc $)$ & 4.0 & 2.7 & 3.5 & 4.2 & 4.7 & 3.5 & 5.8 & 4.7 & 3.9 & NS \\
\hline \multirow[t]{3}{*}{$35-50$} & UEA ( $\alpha 1-2-F u c)$ & 29.6 & 23.5 & 30.4 & 23.0 & 25.2 & 26.2 & 16.9 & 4.3 & 0 & -0.77 \\
\hline & LCA ( $\alpha 1-6-F u c)$ & 29.0 & 31.7 & 23.8 & 15.0 & 16.2 & 18.0 & 10.0 & 12.8 & 11.0 & -0.87 \\
\hline & LTA ( $\alpha 1-3-F u c)$ & 3.1 & 1.9 & 1.6 & 1.7 & 1.6 & 2.2 & 2.8 & 1.5 & 1.5 & NS \\
\hline \multirow[t]{3}{*}{30} & UEA ( $\alpha 1-2-F u c)$ & 12.3 & 14.7 & 13.8 & 9.8 & 8.8 & 11.7 & 14.4 & 9.6 & 9.6 & NS \\
\hline & LCA ( $\alpha 1-6-F u c)$ & 4.1 & 2.9 & 2.6 & 3.0 & 2.0 & 1.9 & 1.9 & 2.9 & 1.8 & -0.75 \\
\hline & LTA ( $\alpha 1-3-F u c)$ & 2.0 & 2.4 & 1.4 & 1.8 & 0.8 & 1.5 & 1.6 & 0.6 & 0 & -0.78 \\
\hline
\end{tabular}

For analysis of fucosylation of milk glycoproteins, the samples were collected only from mothers who have secretor status

The fucosylated bands revealed by lectin- immunoblotting and shown in Fig. 2 were analyzed using myImageAnalysis software (Thermo Scientific, New Hampshire). The relative amounts of fucosyl- glycotopes on each glycoprotein band are expressed as the mean number of pixels $\times 10^{6}$ obtained from two independently done blots

$\mathrm{r}$ - correlation coefficient with lactation days

$N S$ not significant with a $p$-value equal to or higher than $0.05 ; N D$ not determined

$\alpha 1-2$-fucose glycotope. Descending stages happened twice, during the first week and after two weeks of lactation, and they were separated by a week of nearly stable level between 7- and 14 days of lactation. Some small differences in the expression of $\alpha 1-2$ - and $\alpha 1-6$-linked fucoses were probably limited by biological lactation variation caused by inherent interindividual differences among the mothers [46].

In contrast, the expression of $\alpha 1$-3-fucose on milk glycoproteins, if present, was not associated with the milk maturation process. Six of ten milk glycoproteins were weakly recognized by LTA and remained at an unchanged level during milk maturation, three of them did not react (Fig. 3a), whereas a low molecular 30-kDa milk glycoprotein reacted evidently, showing a significant negative correlation with the course of lactation. The high expression of $\alpha 1$-3-linked fucose on the colostrum glycoprotein, 2 days after parturition, might reflect the occurrence of Lewis ${ }^{\mathrm{X}}$ antigen on $30-\mathrm{kDa}$ milk glycoprotein. Its occurrence was probably associated with 
Fig. 3 General pattern of fucosespecific lectin- reactivity of human milk glycoproteins over lactation. The mean value of the relative amounts of the lectinreactive milk glycoproteins was calculated for those showing (a) a significant correlation and (b) no significant correlation with milk maturation. For the calculation, the following SDS-PAGE bands (Table 3) were selected in: (a): reactive with UEA - 220 $225 \mathrm{kDa}, 160-175 \mathrm{kDa}, 35-$ $50 \mathrm{kDa}$; LCA - 260-310 kDa, 160-175 kDa, $133 \mathrm{kDa}, 78$ $86 \mathrm{kDa}, 70-75 \mathrm{kDa}, 35-50 \mathrm{kDa}$, $30 \mathrm{kDa}$; and LTA - $30 \mathrm{kDa}$; and in (b): reactive with UEA - 260-

$310 \mathrm{kDa}, 133 \mathrm{kDa}, 78-86 \mathrm{kDa}$, $70-75 \mathrm{kDa}, 63-67 \mathrm{kDa}, 30 \mathrm{kDa}$; LCA - 220-225 kDa, 63-

$67 \mathrm{kDa}$; , and LTA - 260-310 kDa, 220-225 kDa, 160-175 kDa,

$133 \mathrm{kDa}, 78-86 \mathrm{kDa}, 70-75 \mathrm{kDa}$, 63-67 kDa, 35-50 kDa. For other details see under Table 3
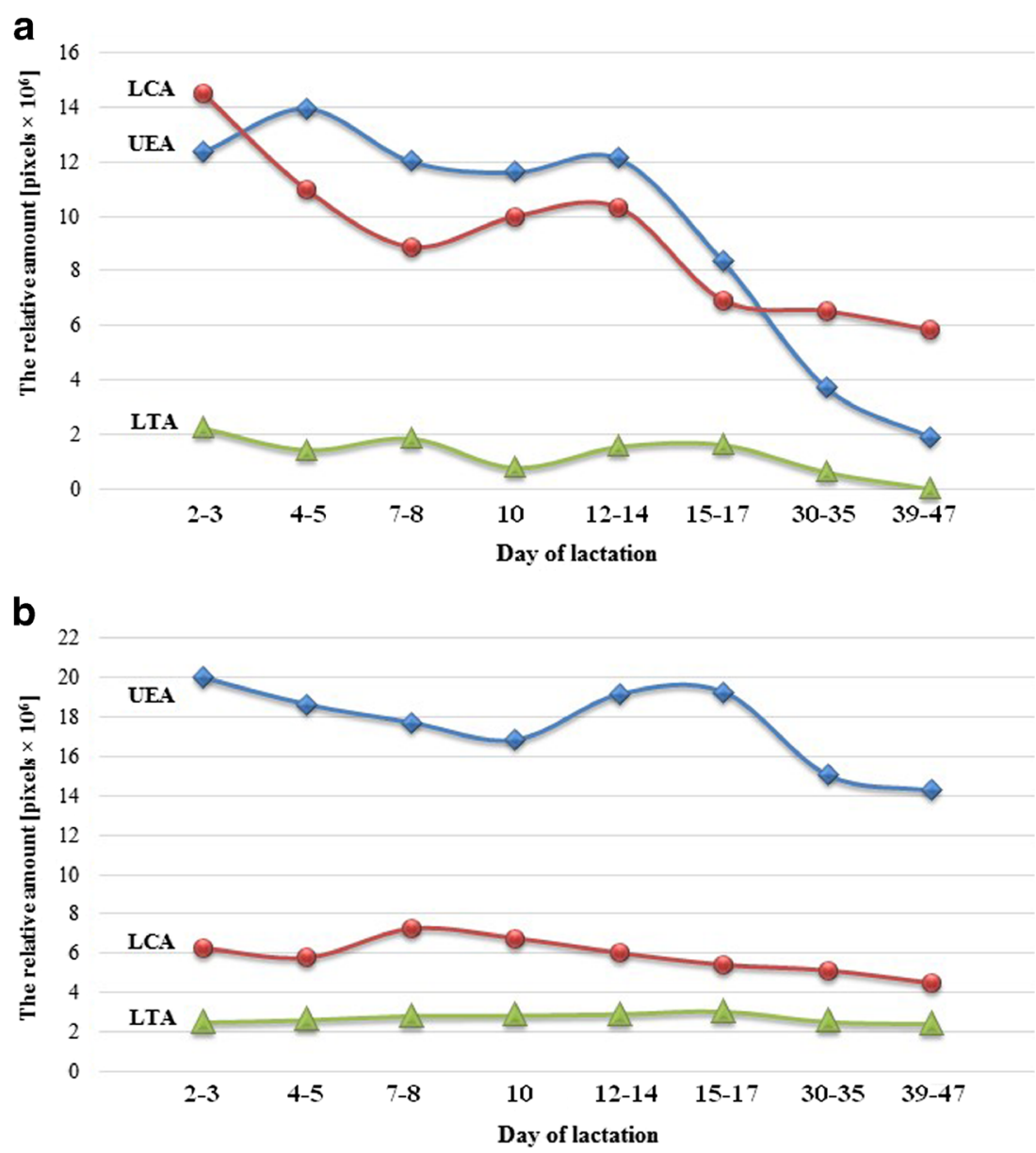

the delivery-induced inflammatory state [47] and hormonal changes [48]. During the following days after delivery, the synthesis of inflammation-induced $\alpha 1-3$-fucosylated Lewis ${ }^{\mathrm{X}}$ glycotope was reduced together with physiological silencing of the perinatal inflammatory processes.

Interestingly, the glycoproteins which have relatively stable expression of $\alpha 1$-2-linked fucose over the course of lactation are probably lactoferrin, the secretory component of IgA (a wide band of 78-86 kDa), ceruloplasmin, pro-epidermal growth factor $(133 \mathrm{kDa})$, and adiponectin $(30 \mathrm{kDa})$ and are reported to play principal roles in innate and adaptive immunity. The $\alpha 1-2$-fucosylation pattern of $220-225$ and $35-$ $50 \mathrm{kDa}$ bands, which may correspond to fibronectin and $\alpha_{1}$ acid glycoprotein, respectively (confirmed by immunoblotting - not shown), overlapped with changes reported previously $[38,39]$.

Among ten bands revealed by LCA- blotting (Fig. 2), two having 78-86 and 35-50- $\mathrm{kDa}$ showed the highest expression of $\alpha 1$-6-fucosylated glycotopes (Table 3). However, over 47 days of lactation the LCA- reactivity of milk glycoproteins significantly decreased and was absent for 260-310, 133, and 70-75 kDa glycoprotein bands.

In spite of the fact that the milk fucosylation pattern can be slightly disturbed by the presence of self-reactive natural blood group antibodies [49] which might precipitate cognate glycoproteins when milk samples were pooled, the characteristic pattern $\alpha 1-2-$ and $\alpha 1-6$-fucosylation of glycoproteins seems to be associated with a significant biological role of these glycotopes. Both are needed during the first days of the newborn's life and are supplied to the breastfed infant. Those decorated by $\alpha 1$-2-linked fucose provide many immunological benefits to the newborn via milk, which include reduced rates of necrotizing enterocolitis, diarrhea, sepsis and urinary tract infections [50]. The $\alpha 1-2$-fucosylated glycotopes of HMOs and glycoproteins can act as ligands for lectin- receptors of bacteria and/or viruses as well as for lectin receptors of newborns' epithelial cells. The 'two-way' participation of human milk glycoproteins in binding and inhibition of pathogen adhesion to the host cells has been confirmed for lactoferrin [51]. Moreover, $\alpha 1$-2-fucosylated glycotopes of human milk glycoproteins, similar to fucosylated HMOs, may take part in improvement of neurocognitive development, promotion of early development of normal bacterial flora in the newborn's gastrointestinal tract and postnatal maturation of intestinal motor activity in infants $[50,52,53]$.

The $\alpha$ 1-6-fucosylated glycotopes on milk glycoproteins, which are absent on HMOs [23], may constitute an additional 
source of the ligand for gastrointestinal tract epithelial lectin receptors and can be considered as a possible modulator of gastrointestinal cell maturation, when the immune system and gastrointestinal tract of the newborn are just beginning to adapt to the new conditions.

The trends observed for major $\alpha 1-2$-fucosylated milk glycoproteins during conversion of immature colostrums throughout transitional to mature milk overlap with those observed for overall fucosylation of HMOs and the levels of $2^{\prime}$ and 3-fucosyllactose [23]. The observed changes in the $\alpha 1-6-$ and $\alpha 1$-2-fucosylation of milk glycoproteins during 7 weeks of normal lactation corresponded to physiological stages of milk maturation. In the first weeks of the newborn's life, the fucosylated glycoproteins given by the mother to the breastfed newborn enrich the immature immune system of the newborn, and they seem to be crucial for the newborn's needs for proper development and well-being. Therefore, human milk of donors and milk formula, particularly for preterm newborns, should correspond to the fucosylation milk profile of healthy mothers.

Acknowledgments This work was supported by the Faculty of Medicine (No Pbmn 137), Wrocław Medical University (Poland).

Conflict of interest The authors declare that they have no conflict of interest.

Open Access This article is distributed under the terms of the Creative Commons Attribution 4.0 International License (http:// creativecommons.org/licenses/by/4.0/), which permits unrestricted use, distribution, and reproduction in any medium, provided you give appropriate credit to the original author(s) and the source, provide a link to the Creative Commons license, and indicate if changes were made.

\section{References}

1. ESPGHAN Committee on Nutrition, Agostoni, C., Braegger, C., Decsi, T., Kolacek, S., Koletzko, B., Michaelsen, K.F., Mihatsch, W., Moreno, L.A., Puntis, J., Shamir, R., Szajewska, H., Turck, D., van Goudoever, J.: Breast-feeding: a commentary by the ESPGHAN committee on nutrition. J. Pediatr. Gastroenterol. Nutr. 49, 112-125 (2009)

2. Wang, B.: Sialic acid is an essential nutrient for brain development and cognition. Annu. Rev. Nutr. 29, 177-222 (2009)

3. Walker, A.: Breast milk as the gold standard for protective nutrients. J. Pediatr. 156, S3-7 (2010)

4. Ruiz-Palacios, G.M., Cervantes, L.E., Ramos, P., Chavez-Munguia, B., Newburg, D.S.: Campylobacter jejuni binds intestinal $\mathrm{H}(\mathrm{O})$ antigen (Fuc alpha 1, 2Gal beta 1, 4GlcNAc), and fucosyloligosaccharides of human milk inhibit its binding and infection. J. Biol. Chem. 278, 14112-14120 (2003)

5. Ruvoën-Clouet, N., Mas, E., Marionneau, S., Guillon, P., Lombardo, D., Le Pendu, J.: Bile-salt-stimulated lipase and mucins from milk of 'secretor' mothers inhibit the binding of Norwalk virus capsids to their carbohydrate ligands. Biochem. J. 393, 627634 (2006)

6. Barboza, M., Pinzon, J., Wickramasinghe, S., Froehlich, J.W., Moeller, I., Smilowitz, J.T., Ruhaak, L.R., Huang, J., Lönnerdal,
B., German, J.B., Medrano, J.F., Weimer, B.C., Lebrilla, C.B.: Glycosylation of human milk lactoferrin exhibits dynamic changes during early lactation enhancing its role in pathogenic bacteria-host interactions. Mol. Cell. Proteomics 11, M111 (2012)

7. Newburg, D.S.: Glycobiology of human milk. Biochemistry (Mosc) 78, 771-85 (2013)

8. Newburg, D.S.: Human milk glycoconjugates that inhibit pathogens. Curr. Med. Chem. 6, 117-127 (1999)

9. Jantscher-Krenn, E., Bode, L.: Human milk oligosaccharides and their potential benefits for the breast-fed neonate. Minerva Pediatr. 64, 83-99 (2012)

10. Liu, B., Newburg, D.S.: Human milk glycoproteins protect infants against human pathogens. Breastfeed. Med. 8, 354-362 (2013)

11. Lis-Kuberka, J., Orczyk-Pawiłowicz, M.: The significance of fucosylated glycoconjugates of human milk in nutrition of newborns and infants. Postepy Hig. Med. Dosw. 69, 811-829 (2015)

12. Gomez, H.F., Ochoa, T.J., Carlin, L.G., Cleary, T.G.: Human lactoferrin impairs virulence of Shigella flexneri. J. Infect. Dis. 187, 87-95 (2003)

13. Bessler, H.C., de Oliveira, I.R., Giugliano, L.G.: Human milk glycoproteins inhibit the adherence of Salmonella typhimurium to HeLa cells. Microbiol. Immunol. 50, 877-882 (2006)

14. Royle, L., Roos, A., Harvey, D.J., Wormald, M.R., van GijlswijkJanssen, D., Redwan, e.-R.M., Wilson, I.A., Daha, M.R., Dwek, R.A., Rudd, P.M.: Secretory IgA N- and O-glycans provide a link between the innate and adaptive immune systems. J. Biol. Chem. 278, 20140-20153 (2003)

15. Becker, D.J., Lowe, J.B.: Fucose: biosynthesis and biologic function in mammals. Glycobiology 13, 41R-53R (2003)

16. Ma, B., Simala-Grant, J.L., Taylor, D.E.: Fucosylation in prokaryotes and eukaryotes. Glycobiology 16, 158R-184R (2006)

17. Orczyk-Pawiłowicz, M.: The role of fucosylation of glycoconjugates in health and disease. Postepy Hig. Med. Dosw. 61, 240-252 (2007)

18. Niwa, R., Natsume, A., Uehara, A., Wakitani, M., Iida, S., Uchida, K., Satoh, M., Shitara, K.: IgG subclass-independent improvement of antibody-dependent cellular cytotoxicity by fucose removal from Asn297-linked oligosaccharides. J. Immunol. Methods 306, 151160 (2005)

19. Perrier, C., Sprenger, N., Corthésy, B.: Glycans on secretory component participate in innate protection against mucosal pathogens. J. Biol. Chem. 281, 14280-14287 (2006)

20. Newburg, D.S.: Neonatal protection by an innate immune system of human milk consisting of oligosaccharides and glycans. J. Anim. Sci. 87, 26-34 (2009)

21. Bernardi, A., Jiménez-Barbero, J., Casnati, A., De Castro, C., Darbre, T., Fieschi, F., Finne, J., Funken, H., Jaeger, K.E., Lahmann, M., Lindhorst, T.K., Marradi, M., Messner, P., Molinaro, A., Murphy, P.V., Nativi, C., Oscarson, S., Penadés, S., Peri, F., Pieters, R.J., Renaudet, O., Reymond, J.L., Richichi, B., Rojo, J., Sansone, F., Schäffer, C., Turnbull, W.B., VelascoTorrijos, T., Vidal, S., Vincent, S., Wennekes, T., Zuilhof, H., Imberty, A.: Multivalent glycoconjugates as anti-pathogenic agents. Chem. Soc. Rev. 42, 4709-4727 (2013)

22. Vestweber, D., Blanks, J.E.: Mechanisms that regulate the function of the selectins and their ligands. Physiol. Rev. 79, 181-213 (1999)

23. De Leoz, M.L., Gaerlan, S.C., Strum, J.S., Dimapasoc, L.M., Mirmiran, M., Tancredi, D.J., Smilowitz, J.T., Kalanetra, K.M., Mills, D.A., German, J.B., Lebrilla, C.B., Underwood, M.A.: Lacto-N-tetraose, fucosylation, and secretor status are highly variable in human milk oligosaccharides from women delivering preterm. J. Proteome Res. 11, 4662-4672 (2012)

24. Day, C.J., Semchenko, E.A., Korolik, V.: Glycoconjugates play a key role in Campylobacter jejuni infection: interactions between host and pathogen. Front Cell Infect. Microbiol. 2, 9 (2012) 
25. Cravioto, A., Tello, A., Villafán, H., Ruiz, J., del Vedovo, S., Neeser, J.R.: Inhibition of localized adhesion of enteropathogenic Escherichia coli to HEp-2 cells by immunoglobulin and oligosaccharide fractions of human colostrum and breast milk. J. Infect. Dis. 163, 1247-1255 (1991)

26. Falk, P., Roth, K.A., Boren, T., Westblom, T.U., Gordon, J.I., Normark, S.: An in vitro adherence assay reveals that Helicobacter pylori exhibits cell lineage-specific tropism in the human gastric epithelium. Proc. Natl. Acad. Sci. U. S. A. 90, 2035-2039 (1993)

27. Liu, B., Yu, Z., Chen, C., Kling, D.E., Newburg, D.S.: Human milk mucin 1 and mucin 4 inhibit Salmonella enterica serovar Typhimurium invasion of human intestinal epithelial cells in vitro. J. Nutr. 142, 1504-1509 (2012)

28. Jiang, X., Huang, P., Zhong, W., Tan, M., Farkas, T., Morrow, A.L., Newburg, D.S., Ruiz-Palacios, G.M., Pickering, L.K.: Human milk contains elements that block binding of noroviruses to human histoblood group antigens in saliva. J. Infect. Dis. 190, 1850-1859 (2004)

29. Naarding, M.A., Ludwig, I.S., Groot, F., Berkhout, B., Geijtenbeek, T.B., Pollakis, G., Paxton, W.A.: Lewis X component in human milk binds DC-SIGN and inhibits HIV-1 transfer to CD4+ T lymphocytes. J. Clin. Invest. 115, 3256-3264 (2005)

30. Saeland, E., de Jong, M.A., Nabatov, A.A., Kalay, H., Geijtenbeek, T.B., van Kooyk, Y.: MUC1 in human milk blocks transmission of human immunodeficiency virus from dendritic cells to T cells. Mol. Immunol. 46, 2309-2316 (2009)

31. Matthies, H., Staak, S., Krug, M.: Fucose and fucosyllactose enhance in-vitro hippocampal long-term potentiation. Brain Res. 725, 276-280 (1996)

32. Murrey, H.E., Gama, C.I., Kalovidouris, S.A., Luo, W.I., Driggers, E.M., Porton, B., Hsieh-Wilson, L.C.: Protein fucosylation regulates synapsin $\mathrm{Ia} / \mathrm{Ib}$ expression and neuronal morphology in primary hippocampal neurons. Proc. Natl. Acad. Sci. 103, 21-26 (2006)

33. Sela, D.A., Garrido, D., Lerno, L., Wu, S., Tan, K., Eom, H.J., Joachimiak, A., Lebrilla, C.B., Mills, D.A.: Bifidobacterium longum subsp. Infantis ATCC $15697 \alpha$-fucosidases are active on fucosylated human milk oligosaccharides. Appl. Environ. Microbiol. 78, 795-803 (2012)

34. Nwosu, C.C., Aldredge, D.L., Lee, H., Lerno, L.A., Zivkovic, A.M., German, J.B., Lebrilla, C.B.: Comparison of the human and bovine milk $\mathrm{N}$-glycome via high-performance microfluidic chip liquid chromatography and tandem mass spectrometry. J. Proteome Res. 11, 2912-2924 (2012)

35. Huang, J., Guerrero, A., Parker, E., Strum, J.S., Smilowitz, J.T., German, J.B., Lebrilla, C.B.: Site-specific glycosylation of secretory immunoglobulin a from human colostrum. J. Proteome Res. 14, 1335-1349 (2015)

36. Froehlich, J.W., Dodds, E.D., Barboza, M., McJimpsey, E.L., Seipert, R.R., Francis, J., An, H.J., Freeman, S., German, J.B., Lebrilla, C.B.: Glycoprotein expression in human milk during lactation. J. Agric. Food Chem. 58, 6440-6448 (2010)

37. Parry, S., Hanisch, F.G., Leir, S.H., Sutton-Smith, M., Morris, H.R., Dell, A., Harris, A.: N-Glycosylation of the MUC1 mucin in epithelial cells and secretions. Glycobiology 16, 623-634 (2006)

38. Orczyk-Pawiłowicz, M., Hirnle, L., Berghausen-Mazur, M., Katnik-Prastowska, I.M.: Lactation stage-related expression of sialylated and fucosylated glycotopes of human milk $\alpha$-1-acid glycoprotein. Breastfeed. Med. 9, 313-319 (2014)

39. Orczyk-Pawiłowicz, M., Hirnle, L., Berghausen-Mazur, M., Kątnik-Prastowska, I.: Terminal glycotope expression on milk fibronectin differs from plasma fibronectin and changes over lactation. Clin. Biochem. 48, 167-173 (2015)

40. Landberg, E., Huang, Y., Strömqvist, M., Mechref, Y., Hansson, L., Lundblad, A., Novotny, M.V., Påhlsson, P.: Changes in glycosylation of human bile-salt-stimulated lipase during lactation. Arch. Biochem. Biophys. 377, 246-254 (2000)

41. Gustafsson, A., Kacskovics, I., Breimer, M.E., Hammarström, L., Holgersson, J.: Carbohydrate phenotyping of human and animal milk glycoproteins. Glycoconj. J. 22, 109-118 (2005)

42. Laemmli, U.K.: Cleavage of structural proteins during the assembly of the head of bacteriophage T4. Nature 227, 680-685 (1970)

43. Towbin, H., Staehelin, T., Gordon, J.: Electrophoretic transfer of proteins from polyacrylamide gels to nitrocellulose sheets: procedure and some applications. Proc. Natl. Acad. Sci. U. S. A. 76, 4350-4354 (1979)

44. Vettermann, C., Jäck, H.M., Mielenz, D.: A colloidal silver staining-destaining method for precise assignment of immunoreactive spots in two-dimensional protein patterns. Anal. Biochem. 308, 381-387 (2002)

45. Katnik, I., Jadach, J., Krotkiewski, H., Gerber, J.: Investigating the glycosylation of normal and ovarian cancer haptoglobins using digoxigenin-labeled lectins. Glycosyl. Dis. 1, 97-104 (1994)

46. Broadhurst, M., Beddis, K., Black, J., Henderson, H., Nair, A., Wheeler, T.: Effect of gestation length on the levels of five innate defence proteins in human milk. Early Hum. Dev. 91, 7-11 (2015)

47. Rinaldi, S.F., Catalano, R.D., Wade, J., Rossi, A.G., Norman, J.E.: Decidual neutrophil infiltration is not required for preterm birth in a mouse model of infection-induced preterm labor. J. Immunol. 192, 2315-2325 (2014)

48. Groër, M.W.: Differences between exclusive breastfeeders, formula-feeders, and controls: a study of stress, mood, and endocrine variables. Biol. Res. Nurs. 7, 106-117 (2005)

49. Djoumerska-Alexieva, I., Manoylov, I., Dimitrov, J.D., Tchorbanov, A.: Serum or breast milk immunoglobulins mask the self-reactivity of human natural IgG antibodies. APMIS 122, 329-340 (2014)

50. Bode, L.: Human milk oligosaccharides: every baby needs a sugar mama. Glycobiology 22, 1147-1162 (2012)

51. Koning, N., Kessen, S.F., Van Der Voorn, J.P., Appelmelk, B.J., Jeurink, P.V., Knippels, L.M., Garssen, J., Van Kooyk, Y.: Human milk blocks DC-SIGN-pathogen interaction via MUC1. Front. Immunol. 6, 112 (2015)

52. Prieto, P.A.: Profiles of human milk oligosaccharides and production of some human milk oligosaccharides in transgenic animals. Adv. Nutr. 3, 456S-464S (2012)

53. Maga, E.A., Weimer, B.C., Murray, J.D.: Dissecting the role of milk components on gut microbiota composition. Gut Microbes 4, 136139 (2013)

54. Audette, G.F., Vandonselaar, M., Delbaere, L.T.: The 2.2 A resolution structure of the $\mathrm{O}(\mathrm{H})$ blood-group-specific lectin I from Ulex europaeus. J. Mol. Biol. 304, 423-433 (2000)

55. Wu, A.M., Lisowska, E., Duk, M., Yang, Z.: Lectins as tools in glycoconjugate research. Glycoconj. J. 26, 899-913 (2009)

56. Kornfeld, K., Reitman, M.L., Kornfeld, R.: The carbohydratebinding specificity of pea and lentil lectins. Fucose is an important determinant. J. Biol. Chem. 256, 6633-6640 (1981)

57. Yan, L., Wilkins, P.P., Alvarez-Manilla, G., Do, S.I., Smith, D.F., Cummings, R.D.: Immobilized Lotus tetragonolobus agglutinin binds oligosaccharides containing the Le $\mathrm{x}$ determinant. Glycoconj. J. 14, 45-55 (1997) 